\title{
The integrated lot sizing and cutting stock problem with saw cycle constraints applied to furniture production
}

\author{
Matheus Vanzela, Gislaine Mara Melega, Socorro Rangel*, Silvio Alexandre de Araujo \\ Departamento de Matemática Aplicada, UNESP-Univ. Estadual Paulista, 15054-000 São José do Rio Preto, SP, Brazil
}

\section{A R T I C L E I N F O}

\section{Keywords:}

Two-dimensional cutting stock

Lot sizing

Integrated problems

Saw cycles constraints

Furniture factory

\begin{abstract}
A B S T R A C T
The integrated lot sizing and cutting stock problem is studied in the context of furniture production. The goal is to capture the interdependencies between the determination of the lot size and of the cutting process in order to reduce raw material waste and production and inventory costs. An integrated mathematical model is proposed that includes lot sizing decisions with safety stock level constraints and saw capacity constraints taking into account saw cycles. The model solution is compared to a simulation of the common practice of taking the lot size and the cutting stock decisions separately and sequentially. Given the large number of variables in the model, a column-generation solution method is proposed to solve the problem. An extensive computational study is conducted using instances generated based on data collected at a typical small scale Brazilian factory. It includes an analysis of the performance of the integrated approach against sequential approaches, when varying the costs in the objective function. The integrated approach performs well, both in terms of reducing the total cost of raw materials as well as the inventory costs of pieces. They also indicate that the model can support the main decisions taken and can bring improvements to the factory's production planning.
\end{abstract}

\section{Introduction}

The Brazilian furniture industry is concentrated in regional centers, mostly situated in the southern and southeastern regions of the country. The state of São Paulo, situated in the southeast, is responsible for $20 \%$ of the national production. The cities of Mirassol and Votuporanga together with their surrounding towns form Local Productive Arrangements (APL - the Portuguese term for Arranjo Produtivo Local), when referring to the production of furniture. These two APL represent about $10 \%$ of the furniture production in the state of São Paulo $[8,33]$. An overview of this sector shows a predominance of micro and small businesses and these are responsible for $61.9 \%$ of the jobs created in the sector. The furniture demand depends on the behavior of different economic factors such as the residential building market, consumer budgets and the stability of the economy, which explain the growth of the Brazilian furniture industry in recent decades.

The sector in Brazil is divided into segments according to the raw materials (e.g. wood, metal and plastic) and the use for which the product is intended (e.g. residential, commercial and institutional). Due to organizational and marketing factors, the companies specialize in one or two types of furniture, such as kitchen and bathroom fittings, bedroom furniture, sofas and armchairs among other groups. Some companies manufacture furniture on a large scale and others are specialized in the production of customized furniture according to specific individualized projects.

The competition among the companies in the sector is directly related to the technology and management tools involved. Also, competition with international markets lead to a series of challenges for the Brazilian furniture industry. One approach to these challenges is to invest large amounts of capital in more sophisticated machines and acquiring new technologies. Making improvements focusing on reducing managerial and manufacturing problems is a less common approach but could be the best solution for survival in a highly competitive market, in particular in the case of small-scale factories that are not able to invest much in their equipment. In fact, the modernization of machinery in these types of factories occurs in stages; it is common to find both new modern machines and outdated ones in the same factory. The visits and interviews conducted in the factories located in the Votuporanga APL showed that good, specialized Decision Support Systems are needed to speed up and improve the production planning decision process.

The production planning in these factories basically involves two main decisions: lot sizing and cutting stock (e.g. $[28,2])$. The lot sizing decisions provide the quantity of furniture to be produced in each

\footnotetext{
* Corresponding author.

E-mail addresses: matheusvanzela@gmail.com (M. Vanzela), gislainemelega@gmail.com (G.M. Melega), socorro@ibilce.unesp.br (S. Rangel), saraujo@ibilce.unesp.br (S.A.d. Araujo).
} 
period of the planning horizon and the cutting decisions generate the best possible cutting patterns to obtain the pieces that make up a final product. When these decisions are taken separately, a large amount of raw material could be used and/or more pieces could be kept in storage. As a result, higher production costs might be incurred.

Taking the lot sizing and the cutting stock decisions simultaneously, there is a possibility of bringing forward the production of some final products and to have better combinations of pieces in cutting patterns, which might decrease the total use of raw material and the total number of pieces in storage. However, this bringing-forward might result in additional holding costs associated to final products and therefore a trade-off between bringing forward and postponing production needs to be considered.

In this paper, a study of the production process of a typical small scale Brazilian furniture factory (Factory L) is conducted and a mathematical model that captures the production process of Factory $\mathrm{L}$ is proposed and tested using instances based on real data. The remainder of this paper is organized as follows. Section 2 presents a review of some papers that are relevant to this work and highlights its main contributions. Section 3 contains a description of the production process in a typical small-scale furniture factory. In Section 4, a mathematical model that considers the integrated lot sizing and the cutting stock decisions is presented as well as a proposal for the simulation of common practice in the factory at the time of the interviews. The solution procedure based on the column-generation technique is presented in Section 5. In Section 6, results of a computational study using instances based on real data conducted to compare the effectiveness of the integrated and the non-integrated solution approaches are presented. This section also presents results that show the impact on the models when the costs in the objective function are changed. Section 7 presents concluding remarks.

\section{Review of related papers}

Lot sizing and cutting stock are two well-known problems that have attracted the attention of the production and operations research scientific community in terms of case studies, models and efficient solution methods $[20,18,38]$.

However, only a few papers have considered their integration, also known in the literature as the combined lot sizing and cutting stock problem. Among them, Farley [6] is the first author to publish an integrated cutting stock and production planning problem. The problem is considered in the context of clothing production. Hendry et al. [16] present a two stage solution procedure for the integrated cutting stock and lot sizing problem in the context of copper production. In the first stage, the cutting stock problem with capacity constraints is solved heuristically. The solution of stage one is then used in an integer programming model to determine the lot sizes. Arbib and Marinelli [3] consider a mixed integer programming model to solve the integrated problem. The proposed model allows for the cutting of non-ordered pieces that may be later grouped to meet future demand (cut-andreuse). The model also includes inventory and transportation costs. Nonas and Thorstenson [21,22] consider a one-dimensional cutting stock problem with holding costs and setup costs associated to cutting patterns. In Nonas and Thorstenson [21] a column generation procedure is proposed with good results for small scale problems. They extend their paper and, in Nonas and Thorstenson [22], the ideas presented in Haessler [15] are considered and the column generation procedure is improved with good results for small and large scale problems. Applications of the integrated problem in the paper industry can be found in Respício and Captivo [27] and Poltroniere et al. [25].

The integrated problem applied in the context of furniture production is presented in Gramani and França [12], Gramani et al. [13], Silva et al. [30], Gramani et al. [14], Alem and Morabito [1,2] and Silva et al. [32]. In Gramani and França [12] the authors analyze the multi-period cutting stock problem where the goal is to minimize the total number of plates used in the cutting process, the inventory costs of pieces and the setup costs, but they do not consider the production and inventory costs of final products. They propose a solution method based on an analogy with the shortest path problem. Gramani et al. [13] extend the model proposed in Gramani and França [12] by including the decisions about the final products. They propose a heuristic method based on Lagrangian relaxation applied to the integrated lot sizing and cutting stock problem. The difficulty faced by the Lagrangian solution approach is that the resulting Lagrangian subproblems are NP-hard capacitated lot sizing problems. Gramani et al. [14] address the model proposed in Gramani et al. [13] by relaxing setups and maintaining the storage of pieces. They consider a trade-off between pieces inventory and raw material waste. For solving this integrated model, they use the CPLEX package with a column generation technique. Silva et al. [30] consider the capacity of the cutting machine and of the drilling machines. They relax the integrality of the setup variables, and use the Simplex method with column generation to deal with the enormous quantity of cutting patterns. Alem and Morabito [1,2] apply robust optimization tools to the integrated lot sizing and cutting stock models considering production costs and product demands as stochastic parameters. Silva et al. [32] proposed two integer programming models to optimize a production process in a furniture industry. The proposed models allow the inventory of items and leftovers, which can be used in subsequent periods. The first model is an extension of the model proposed in a previous research [31]. The second model is based on the model proposed by Dyckhoff [5] for the one-dimensional cutting stock problem (called one-cut), where each decision variables corresponds to a single cutting operation in a single object. Computational results are presented using real data from a furniture industry.

Still related with the present work, we mention that Wagner [37] discusses the cutting stock problem in which lumber is cut in bundles; Henn and Wäscher [17] and Cui et al. [4] study the cutting stock problems with reduction on the number of different cutting patterns; and Poldi and de Araujo [23] consider the multiperiod cutting stock problem.

In this paper, we present a new mathematical model to integrate the lot sizing and the cutting stock decisions in the context of furniture production of small factories. The main difference from other models proposed in the literature is the consideration of safety stock level of final products and capacity constraints taking into account saw cycles. This last characteristic is important because the cutting machine allow the simultaneous cutting of several plates. That is, the plates can be stacked in the machine so that they can be cut simultaneously according to the same cutting pattern. The total number of plates that can be stacked depends on the machine maximum load and on the thickness of the plates. The time necessary to adjust the cutting machine and to cut a stack of objects according to a given cutting pattern is named saw cycle $[39,34]$. So, the total number of saw cycles is an important aspect to be considered when solving the cutting stock problem.

In summary the paper has the following contributions. First, the proposal of an innovative integrated model. Second, the simulation of the practice of small-scale furniture factories through mathematical models that considers the sequential decisions, i.e., first taking the lot sizing decision and afterwards the cutting stock decision. Third, the proposal of a solution method based on column-generation for solving the mathematical models. Finally, the presentation of computational results that show the quality of the proposed integrated approach when compared to a simulation of the factory practice, as well as a study of the impact of cost variations on the different approaches.

This paper extends the initial research published in Santos et al. [28] and in Vanzela et al. [36]. In the latter a relaxed version of the saw cycle constraint is considered and limited computational results are presented. Santos et al. [28] consider a detailed cutting machine capacity and an approximated capacity of the remaining production process. The operational details considered are the setup time for 
cutting patterns changeover and saw machine capacity in terms of the number of plates that can be simultaneously cut. They solve the problem using a rolling horizon strategy and present results for just two instances considering only a set of a priori defined cutting patterns.

\section{The furniture production process in small-scale factories}

The focus of this work is on factories that produce rectilinear furniture using as its main raw material rectangular wooden plates such as MDF (Medium-Density Fiberboard), OSB (Oriented Strand Board) and other similar materials. The furniture production process described below is based on the information collected at Factory $\mathrm{L}$ situated at the Votuporanga APL, a typical small scale Brazilian factory according to a classification based on the number of employees [29]. The furniture production process involves several stages and equipment, the different types of equipment are grouped in sectors according to their function and the production stage. The main differences in the production process of Factory $\mathrm{L}$ and of the other companies visited are in specific stages of the production process or in the modernity of certain equipment.

The production floor at Factory $\mathrm{L}$ is divided into four main sectors: cutting, woodwork, painting and dispatching. At the first stage (cutting), the required number of plates are cut to produce the pieces that compose each final product. At the time the data was collected, the cutting sector had one automatic cutting machine (main) and one semiautomatic one (secondary) which is used only at peak periods or during maintenance of the main machine.

After cutting the plates, the pieces move on to the woodworking sector. Several operations are conducted in this sector. Some rectangular pieces are processed to form non rectangular shapes according to the product design. All pieces pass through some type of finishing in order to take out any irregularities, and some of them receive edge finishing. The drilling operations are also done is this sector. Due to the precision needed in these operations, the woodworking area is crucial and the quality control must be rigorous. Once the pieces go through all the necessary woodwork operations they are ready to be painted.

The painting sector houses two types of painting (i) Polyurethane (PU) painting, which is a manual process and (ii) Ultraviolet (UV) painting, which is semi-automatic. This area also includes the sanding and cleaning operations. To end the production process, the painted pieces go to the dispatching sector where they are packed according to the final product specifications, labeled and stored for future delivery. Fig. 1 shows the production flow at Factory L. More information about the furniture production process can be found in Vanzela [35] and the references therein.

The Factory L catalogue considered in this study contains eight types of furniture: a multi-cabinet, a dressing table and six different models of wardrobe, from now on named as MC, DT and W1 to W6, respectively. The furniture can be produced in seven different single colors or in a combination of two colors, resulting in over 150 different final products. At the time the data was collected, two products (W4,W6) represented $50 \%$ of total sales and thus they received more attention in the production process.

Each final product is composed of a number of rectangular pieces cut from rectangular plates of different thicknesses. The type and number of pieces necessary to obtain one final product represents a major concern for the production manager. Besides the associated cutting stock decision, the total number of pieces will influence other decisions such as total number of drilling operations, final product cost, packaging and transportation. The number of pieces that compose each final product ranges from six to twenty. Some of these products share the same pieces (in terms of size and thickness). This information must be taken into account when considering a combination of final products in the same lot.

From the above description, it is possible to infer that the

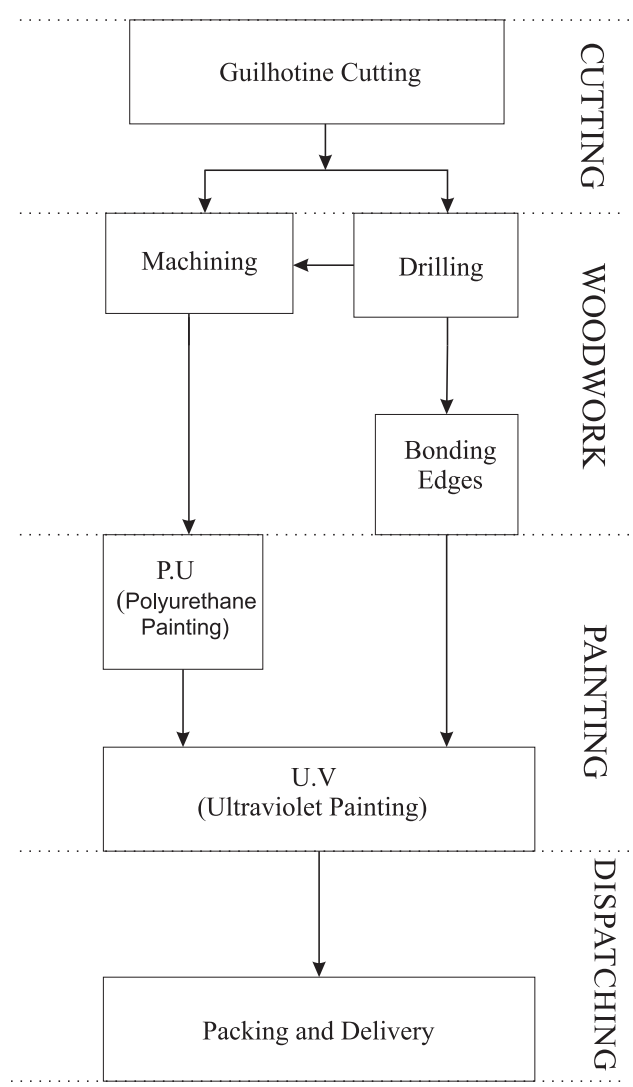

Fig. 1. Furniture production flow diagram.

production manager has a difficult task when taking the lot sizing and the cutting stock decisions. These decisions are taken weekly based on the forecast demand, the sales of similar periods in previous years and on the results of marketing campaigns already in progress. Also, the factory has previous commitments to meet and therefore efficient production planning and control is mandatory. The main concern of the production managers of the factories visited is the final product cost. According to the Factory L data, the main raw material (wooden plates) costs represent $50 \%$ of the final product cost.

\section{Mathematical model for the Integrated Lot Sizing and Cutting Stock Problem for Furniture Production (ILSCSP)}

In this section, we present a new mathematical model for the integrated lot sizing and cutting stock problem. The model is based on the description of the production process of small scale furniture factories presented in Section 3. Before stating the problem and presenting the mathematical model, some simplifications to the production process are considered to obtain a computer solvable model.

Simplifications:

1. Only the cutting sector capacity is considered and it is assumed that the other sectors can handle the decisions taken for the cutting stock problem. This is a common assumption in the literature because in most of the furniture plants the cutting sector is the bottleneck of the production process. We have found nine papers in the literature that consider the integrated lot sizing and cutting stock problem applied to furniture industry. Five of them (Gramani and França [12], Gramani et al. [13,14], Alem and Morabito [1] and Vanzela et al. [36]) consider capacity constraints only in the cutting sector, as we do. Three of them (Silva et al. [30], Santos et al. [28] and Alem and Morabito [2]) consider capacity constraints in the cutting sector and also in the drilling sector. Silva et al. [32] do not consider capacity 
constraints. Furthermore, Toscano et al. [34] focus specifically on the optimization of the cutting sector of Factory L, which shows the relevance of the cutting sector in furniture industries and that this is a realistic simplification.

2. Setup time for the cutting machine was not taken into account, nor was the cutting patterns changeover time. The estimated impact of these simplifications is taken into account indirectly on the cutting machine capacity.

3. Late delivery and overtime working to meet demand are not allowed.

4. The colors of the final products are not considered.

Considering the simplifications (1)-(4) and a planning horizon divided into periods, the integrated problem considered in this study can be stated as: determine the lot size of final products, the total number of plates and cutting patterns necessary to obtain the pieces that compose the final products, taking into account the demand of each final product in each period, the cutting machine capacity and safety stock levels for final products. The decisions are taken aiming to minimize the overall costs computed in terms of production and inventory costs of the final products, plates cost and pieces inventory costs.

The usual practice of the majority of the factories visited is to divide this problem in two sequential problems. First they solve the lot sizing problem to define the quantities of final products. After that they obtain the total number of pieces necessary to compose the final products and then solve the cutting stock problem to decide the total number of plates to be cut and the associated cutting patterns.

The process of cutting the plates may involve waste of material. The factory is interested in reducing this waste given that it has a strong impact on the cost of the final product. One way of reducing this waste is by increasing the number of types of ordered pieces. A wider variety of pieces may allow for a better arrangement of the pieces on the plate (cutting pattern). Moreover, increasing the demand for given pieces might help to reduce the number of saw cycles due to the fact that more plates may be cut simultaneously with the same cutting pattern. All this can be achieved if the factory brings forward the production of some final products. However, this early production may incur additional inventory costs. To best capture all these cutting stock and lot sizing elements in the decision process, an integrated decision should be taken.

\subsection{The model description}

To define the integrated mathematical model, let $T$ be the number of periods in the planning horizon and $F$ be the total number of ordered final products. As stated in Section 3, one final product is composed of rectangular pieces of different thicknesses cut from rectangular wooden plates. So, let $E$ be the total number of different plates or pieces thicknesses, and $P$ the total number of pieces. We consider that the stock of rectangular plates of each different thickness is enough to meet all the pieces demand, and that they are all of the same length $(L)$ and width $(W)$. To simplify the model description, we will consider that $J$ is the number of all possible cutting patterns (pre-supposing that these cutting patterns have been generated a priori considering all the pieces necessary to obtain the final products). Since two dimensions are relevant in the cutting processes, the cutting patterns in this context are classified as two-dimensional.

The following indices are used to define the parameters, constraints and variables used in the model.

Indices:

$t=1, \ldots, T$ : periods;

$f=1, \ldots, F$ final products (or simply products below);

$p=1, \ldots, P$ pieces;

$e=1, \ldots, E$ plate thickness;

$j=1, \ldots, J$ cutting patterns.
The following parameters are presumed to be known.

\section{Parameters:}

$c_{f} \quad$ production cost for product $f$

$h_{f} \quad$ inventory cost for product $f$;

$D_{f t} \quad$ demand for product $f$ in period $t$;

$C_{t} \quad$ maximum production capacity in period $t$, computed in number of saw cycles.

$o^{e} \quad$ thickness of plate $e$;

co $^{e} \quad$ cost of the plate with thickness $e$;

$S \quad$ height of the saw;

cap $^{e} \quad$ maximum number of plates of thickness $e$ that can be simultaneously cut $\left(\operatorname{cap}^{e}=\left\lfloor\frac{S}{o^{e}}\right\rfloor\right)$;

$\hat{h}_{p}^{e} \quad$ inventory cost of piece $p$ with thickness $e$;

$q_{p f}^{e} \quad$ number of pieces $p$ of thickness $e$ necessary to produce one unit of product $f$

$L: \quad$ length of the plates;

$W$ : $\quad$ width of the plates;

$l_{p}^{e} \quad$ length of piece $p$ with thickness $e$;

$w_{p}^{e} \quad$ width of piece $p$ with thickness $e$;

$a_{p j}^{e} \quad$ number of pieces $p$ with thickness $e$ in the cutting pattern $j$;

$I_{f 0} \quad$ initial inventory of product $f$;

$I P_{p 0}^{e} \quad$ initial inventory of piece $p$ with thickness $e$;

ts demand percentage used to impose safety stock level of products;

tx parameter used to adjust the approximated capacity.

The following variables are used to model the decisions associated with the mathematical model.

\section{Variables:}

$X_{f t} \quad$ number of product $f$ produced in period $t$;

$I_{f t} \quad$ number of product $f$ stored at the end of period $t$

$I P_{p t}^{e} \quad$ number of pieces $p$ of thickness $e$ stored in period $t$;

$y_{j t}^{e} \quad$ number of plates of thickness $e$, cut according to cutting pattern $j$ in period $t$;

$z_{j t}^{e} \quad$ number of saw cycles necessary to cut plates of thickness $e$ according to cutting pattern $j$ in period $t$.

The proposed integrated lot sizing and cutting stock model consists of coupling the characteristics and considerations for both the lot sizing and the cutting stock decisions in a single model that is defined by the expressions (1)-(10).

The ILSCSP model

$\operatorname{Min} Z=\sum_{f=1}^{F} \sum_{t=1}^{T}\left(c_{f} X_{f t}+h_{f} I_{f t}\right)+\sum_{e=1}^{E} \sum_{j=1}^{J} \sum_{t=1}^{T} c o^{e} y_{j t}^{e}+\sum_{e=1}^{E} \sum_{p=1}^{P} \sum_{t=1}^{T} \hat{h}_{p}^{e} I P_{p t}^{e}$

Subject to:

$X_{f t}+I_{f, t-1}-I_{f t}=D_{f t} \quad f=1, \ldots, F ; t=1, \ldots, T$

$I_{f t} \geq t s D_{f t} \quad f=1, \ldots, F ; t=1, \ldots, T-1$

$I_{f T} \geq t s\left(\sum_{t=1}^{T} D_{f t}\right) \quad f=1, \ldots, F$

$\sum_{j=1}^{J} a_{p j}^{e} y_{j t}^{e}+I P_{p, t-1}^{e}-I P_{p t}^{e}=\sum_{f=1}^{F} q_{p f}^{e} X_{f t} \quad p=1, \ldots, P ; \quad t=1, \ldots, T$

; $e=1, \ldots, E$ 


$$
\begin{aligned}
& \sum_{e=1}^{E} \sum_{j=1}^{J} z_{j t}^{e} \leq C_{t} \quad t=1, \ldots, T \\
& z_{j t}^{e} \geq \frac{y_{j t}^{e}}{\operatorname{cap}^{e}} \quad j=1, \ldots, J ; t=1, \ldots, T ; e=1, \ldots, E \\
& X_{f t}, I_{f t} \in \mathbb{R}_{+} \quad f=1, \ldots, F ; t=1, \ldots, T \\
& z_{j t}^{e} \in \mathbb{Z}_{+}, y_{j t}^{e} \in \mathbb{Z}_{+} \quad j=1, \ldots, J ; t=1, \ldots, T ; e=1, \ldots, E \\
& I P_{p t}^{e} \in \mathbb{R}_{+} \quad p=1, \ldots, P ; t=1, \ldots, T ; e=1, \ldots, E
\end{aligned}
$$

- Objective function (1): the optimization criterion is the minimization of the total cost calculated by the sum of the production costs $\left(c_{f}\right)$, inventory costs of products $\left(h_{f}\right)$, raw material costs $\left(c o^{e}\right)$ and inventory costs of pieces $\left(\hat{h}_{p}^{e}\right)$. This expression translates the tradeoff that should be achieved considering the costs of production, inventory of products and of pieces as well as the cost of the plates.

- Meeting demand constraints (2): these constraints guarantee that the demand for products $f\left(D_{f t}\right)$ is met by balancing the production in period $t$, the inventory from the previous period $(t-1)$, and the unshipped products that remain in inventory in period $t$ for later use.

- Safety stock level constraints (3) and (4): these constraints impose safety stock levels for the product $f$ as a percentage of the demand for each product. For the first $(T-1)$ periods, the safety levels are stated in terms of the individual demands $\left(t s D_{f t}\right)$, and for the final period, the safety stock levels are stated in terms of the total demands $\left(t s\left(\sum_{t=1}^{T} D_{f t}\right)\right)$.

- Coupling constraints (5): these constraints model the interdependence between the decisions. They take into account the decisions relative to lot sizing ( $X_{f t}$ variables) to determine the pieces demand and thus the decisions relative to the cutting of raw material $\left(y_{j t}{ }^{e}\right.$ variables). It allows for the possibility of storing pieces (IP ${ }_{p t}$ variables).

- Saw cycles capacity constraints (6): these constraints guarantee that no more than $C_{t}$ saw cycles are used in each period $t$.

- Minimum number of saw cycles constraints (7): these constraints impose a lower bound to the number of cycles necessary to cut the $\mathrm{y}_{j t}{ }^{e}$ plates of thickness $e$ according to the cutting pattern $j$ in period $t$ taking into account the cutting machine maximum load (cap ${ }^{e}$ ).

- Variable domain constraints (8)-(10): these constraints determine the domains of the variables. It is usual that the lot size decisions $X_{f t}$ are defined as continuous variables.

It is important to highlight that, in general, when stating lot sizing constraints it is assumed that the safety stock levels are implicit in the demand. The safety stock level constraints (3) and (4) differ from this standard practice because the imposition of safety stock levels is smaller in the first $(T-1)$ periods, thus allowing more freedom to allocate the initial inventory to meet demand in any of these periods. The total number of constraints present in the ILSCSP model is given by $(F T+F(T-1)+F+P T E+T+J T E)$ and the total number of variables is given by $(2 J T E+2 F T+P T E)$.

\subsection{Simulation of the factory production planning process}

The coupling of the lot sizing and the cutting stock decisions in the ILSCSP model are achieved by imposing constraints (5). If these constraints are removed, the model decomposes into two independent models that can be used to simulate the usual factory practice. The remaining constraints will be used to define the Lot sizing problem and the Cutting Stock problems that are solved sequentially in practice. Still, to be realistic, the resulting models have to take into account some elements of each other. In what follows, we will describe the models that will be used to simulate the practice in Factory L.

\subsubsection{Model for the Capacitated Lot Sizing Problem for furniture production (CLSP)}

The mathematical model (11)-(16) is used to simulate the lot sizing decisions in the context of furniture production. It determines the lot sizes for the products (furniture) as well as the inventory levels in each period of the planning horizon aiming to minimize the total cost of production and inventory of the products. It uses the same indices, parameters and variables as the ILSCSP model.

The CLSP model:

$\operatorname{Min} Z=\sum_{f=1}^{F} \sum_{t=1}^{T}\left(c_{f} X_{f t}+h_{f} I_{f t}\right)$

Subject to:

$X_{f t}+I_{f, t-1}-I_{f t}=D_{f t} \quad f=1, \ldots, F ; t=1, \ldots, T$

$t x\left(\sum_{f=1}^{F} \sum_{e=1}^{E} \frac{\left(l_{p}^{e} \cdot w_{p}^{e}\right) q_{p f}^{e} X_{f t}}{(L \cdot W) c a p^{e}}\right) \leq C_{t} \quad t=1, \ldots, T$

$I_{f t} \geq t s D_{f t} \quad f=1, \ldots, F ; t=1, \ldots, T-1$

$I_{f T} \geq t s\left(\sum_{t=1}^{T} D_{f t}\right) \quad f=1, \ldots, F$

$X_{f t}, I_{f t} \in \mathbb{R}_{+} f=1, \ldots, F ; t=1, \ldots, T$

- Objective function (11): the optimization criterion is the minimization of total costs considering production $\left(c_{f}\right)$ and inventory costs $\left(h_{f}\right)$.

- Saw capacity constraints (13): to obtain a realistic decision, an estimate of the cutting machine capacity is considered. This constraint is stated considering that the pieces can be cut from an imaginary single plate with enough area to cut all the necessary pieces. Then the approximated total number of plates necessary to produce $\left(X_{f t}\right)$ products is obtained by dividing the total area used for this imaginary plate divided by the real plate area: $\left(\sum_{f=1}^{F} \sum_{e=1}^{E} \frac{\left(l_{p}^{e} \cdot w_{p}^{e}\right) q_{f f}^{e} X_{f t}}{(L \cdot W)}\right)$. The parameter $\operatorname{cap}^{e}=\left\lfloor\frac{S}{o^{e}}\right\rfloor$ allows the transformation of the used capacity into number of saw cycles. In this way, the definition of the furniture lot sizes takes into account an approximation of the total number of saw cycles necessary to cut all the pieces.

- The constraints (12), (14), (15), (16) have the same purpose as the constraints (2), (3), (4), and (8) in the ILSCSP model, respectively.

4.2.2. Model for the multi-period Cutting Stock Problem for a furniture factory (CSP)

The cutting stock model (CSP) described by (17)-(22) uses a feasible solution of the lot sizing model $(C L S P)\left(\widetilde{X}_{f t}\right)$ to compute the pieces demand. The CSP model then determines the number of plates to be cut and the associated cutting patterns to meet the pieces demand aiming to minimize the total cost of plates and pieces inventory. It uses the same indices, parameters and variables as the ILSCSP model.

The CSP model

Min $Z=\sum_{e=1}^{E} \sum_{j=1}^{J} \sum_{t=1}^{T} \operatorname{co}^{e} y_{j t}^{e}+\sum_{e=1}^{E} \sum_{p=1}^{P} \sum_{t=1}^{T} \hat{h}_{p}^{e} I P_{p t}^{e}$

Subject to:

$$
\begin{aligned}
\sum_{j=1}^{J} a_{p j}^{e} y_{j t}^{e}+I P_{p, t-1}^{e}-I P_{p t}^{e}= & \sum_{f=1}^{F} q_{p f}^{e} \widetilde{X}_{f t} \quad p=1, \ldots, P ; t=1, \ldots, T \\
& ; e=1, \ldots, E
\end{aligned}
$$




$$
\begin{aligned}
& \sum_{e=1}^{E} \sum_{j=1}^{J} z_{j t}^{e} \leq C_{t} \quad t=1, \ldots, T \\
& z_{j t}^{e} \geq \frac{y_{j t}^{e}}{\operatorname{cap}^{e}} \quad j=1, \ldots, J ; \quad t=1, \ldots, T ; e=1, \ldots, E \\
& z_{j t}^{e} \in \mathbb{Z}_{+}, y_{j t}^{e} \in \mathbb{Z}_{+} \quad t=1, \ldots, T ; j=1, \ldots, J ; e=1, \ldots, E \\
& I P_{p t}^{e} \in \mathbb{Z}_{+} p=1, \ldots, P ; t=1, \ldots, T ; e=1, \ldots, E
\end{aligned}
$$

- Objective function (17): minimize the total cost considering the plates cost and the inventory cost of pieces.

- Meeting pieces demand constraints (18): these constraints guarantee that, in each period, the pieces demand $\left(\sum_{f=1}^{F} q_{p f}^{e} \widetilde{X}_{f t}\right)$ is met by balancing the number of pieces produced in period $t\left(\sum_{j=1}^{J} a_{p j}^{e} y_{j t}^{e}\right.$, ), the pieces stored in the previous period $\left(I P_{p, t-1}^{e}\right)$, and the unused pieces that are stored in period $t\left(I P_{p t}{ }^{e}\right)$ for later use.

- The constraints (19), (20), (21), (22) have the same purpose as the constraints (6), (7), (9) and (10) in the ILSCSP model, respectively.

The problem (17)-(22) extends, by considering saw cycle constraints and two dimensions, the multiperiod cutting stock problems that have been considered in the literature, for example, in Poldi and Arenales [24].

\section{Solution method}

Instances of the CLSP model can be solved easily by the available solvers. However, the instances of the ILSCSP and CSP models can not be solved easily due to the high number variables $y_{j t}^{e}$ (possible cutting patterns) and their integral nature. To get round these difficulties, a column-generation method based on Gilmore and Gomory $[9,10]$ is applied to a relaxed linear model that is obtained by substituting the constraint $y_{j t}^{e} \in \mathbb{Z}_{+}$by $y_{j t}^{e} \in \mathbb{R}_{+}$.

We will describe the column generation procedure considering the ILSCSP. An equivalent procedure is applied to the CSP. The Restricted Master Problem (RMP) for the ILSCSP is defined taking only a subset of $\left(T^{*} P^{*} E\right)$ cutting patterns in the sub-matrix associated to the variables $y_{j t}{ }^{e}$. The remaining $\left(J-T^{*} P^{*} E\right)$ cutting patterns (and the associated variables $y_{j t}{ }^{e}$ ) are removed from the problem and will be generated as necessary. All the columns related to the other variables are included in the RMP, except the variables $z_{j t}{ }^{e}$ which are created as the associated variables $y_{j t}{ }^{e}$ are generated.

The current $R M P$ is solved and the dual variables $\pi_{t}^{e}$ associated to constraints (5) are recovered. For each thickness $e$ and period $t$ the pricing sub-problem (23) and (24) is solved to identify if there are cutting patterns $\left(A_{j}^{e}\right)$ that can improve on the current $R M P$ solution. To simplify the notation, the index $t$ is omitted in the dual variables $\pi^{e}{ }_{t}$ :

$Z_{S U B}=\max \quad \pi^{e} A_{j}^{e}$

s. t. $A_{j}^{e}$ is a two-dimensional cutting pattern

The columns that satisfy the criterion determined by the reduced cost (25) are included in the $R M P$ and the new $R M P$ is solved. This iterative process is repeated until no more new columns that satisfy this criterion are generated:

$\hat{c}_{j t}^{e}=c o^{e}-Z_{S U B}<0$,

When the generated columns no longer price out, a reduced version of the model (1)-(10) is built considering a subset of cutting patterns. Only the $\mathrm{y}_{j t}^{e}$ and the $z_{j t}{ }^{e}$ variables associated to the initial cutting patterns and the cutting patterns generated for the $R M P$ are included in constraints (5)-(7). This reduced mixed integer model is then solved using a commercial optimization software package to obtain a feasible mixed integer solution for the integrated problem.

Several aspects should be considered in the generation of cutting patterns [40]. The majority of cutting machines observed in the furniture factories impose that only orthogonal guillotine cuts can be made. A cut is of orthogonal guillotine type if, when applied to a rectangle, it produces two other rectangles. Another important consideration is the number of times the plate must be rotated in $90^{\circ}$ in order to cut all the pieces. This is called the number of stages. If, at the end of the final stage, all the items have been obtained, the cutting pattern is exact, otherwise it is said to be non-exact. The trimming in a non-exact cutting pattern is usually done in a secondary cutting machine and therefore it is not counted as an additional stage [19]. An important class of orthogonal guillotine cutting pattern with high productivity of the cutting machine is the n-group cutting pattern. An $n$-group cutting pattern is formed by $n$ parts of 1 -group patterns. A 1group pattern is a two-stage cutting pattern formed by a set of strips that can be simultaneously cut in the second stage [11].

A special case of the 1-group cutting pattern is the maximal homogeneous cutting pattern, i.e. a cutting pattern that contains only one type of piece, the maximum possible number. The maximal homogeneous cutting pattern $j$ associated to piece $p$ of thickness $e$ can be represented by the column vector $\left(A_{j}^{e}\right)^{t}=\left(0, \ldots, a_{p p}^{e}, \ldots, 0\right)$, $a_{p p}^{e}=\left\lfloor\frac{L}{l_{p}^{e}}\right\rfloor\left\lfloor\frac{W}{w_{p}^{e}}\right\rfloor$. The set of $P$ maximal homogeneous cutting patterns is used to initialize the RMP and guarantees an initial solution that attend the pieces demand.

Other methods can be used to obtain feasible two-dimensional cutting patterns in the pricing sub-problem (23) and (24) (e.g. $[10,40])$. Regarding the context of furniture production, there are some papers in the literature that consider the stand alone cutting stock problem and propose different approaches to generate orthogonal guillotine two-dimensional cutting patterns [26,40,41,19]. In particular, Rangel and Figueiredo [26] analyze the cutting patterns used in Factory L and present a heuristic procedure to generate cutting patterns based on $n$-group patterns that simulates the ones used in the factory practice. A comparison of the heuristic solution with the solution given by the factory indicates that the proposed heuristic can generate cutting patterns similar to the ones used in the factory with equal or less waste. Besides the homogenous cutting patterns used to initialize the $R M P$, in this paper we considered only 2-group cutting patterns. Fig. 2 shows an example of a 1-group and of a 2-group cutting patterns, the latter was generated and used in Factory $\mathrm{L}$.

\section{Computational study}

The objective of the computational study described in this section is to analyze the behavior of the proposed model. The three mathematical models (ILSCSP, CLSP, and CSP) and the column-generation algorithm (described in Sections 4 and 5 respectively) were written in the syntax of the Mosel modeling language and the associated optimization problems were solved using the solver X-PRESS ${ }^{M P}$ [7]. The runs were executed on a machine with $8.0 \mathrm{~GB}$ of RAM and an Intel(R) Core(TM) i-7 chip at $3 \mathrm{GHZ}$.

For the sake of comparison to the integrated model ILSCSP, and following the company's decision making process, first the CLSP is solved and its solution is used to determine the pieces demand. Then the multi-period cutting stock problem CSP is solved. The maximum execution time for solving the integrated model (ILSCSP) was set to $3600 \mathrm{~s}$. The same amount of time was given for solving the separated models $(C L S P+C S P)$, being $60 \mathrm{~s}$ for the $C L S P$ model and $3540 \mathrm{~s}$ for the $C S P$ model. The time given for solving each pricing sub-problem (in models ILSCSP and CSP) was $60 \mathrm{~s}$. In order to evaluate the impact of the capacity constraint on the lot-sizing decisions, we also considered a fourth model built removing the capacity constraint (13) from the CLSP model, denoted by LSP. The computational study is divided in two parts. The results presented in Section 6.2 consider the instances 


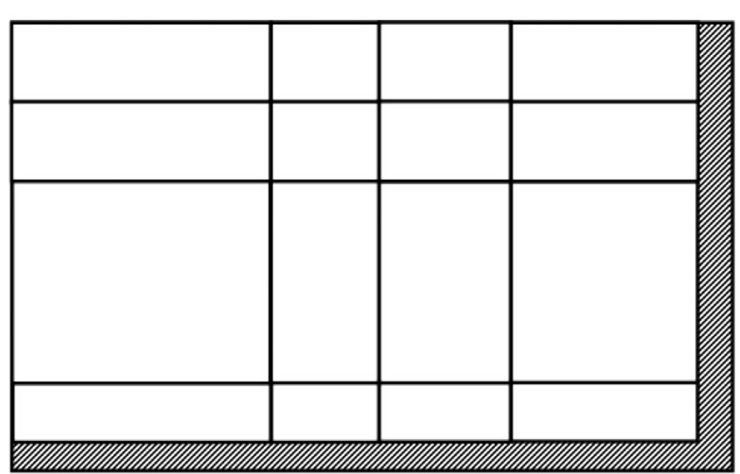

(a) A 1-group cutting pattern

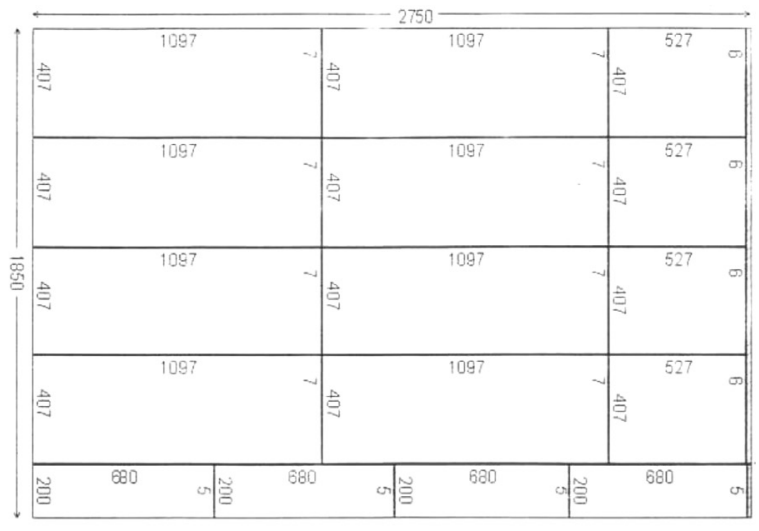

(b) A 2-group cutting pattern from Factory L

Fig. 2. Examples of 1-group and 2-groups cutting patterns.

generated with the data set described in Section 6.1. The results presented in Section 6.3 consider new instances generated by varying the costs in the objective function.

\subsection{Data set}

In the data set we consider that one period of time is equivalent to one week and, for each instance, we considered a planning horizon of 4 weeks (1 month). Fifteen instances were generated based on data collected at Factory $\mathrm{L}$ and from the furniture market considering the months of March (instances 1-5), August (instances 6-10) and November (instances 11-15). These months represent, low, medium and high demand respectively according to the seasonality of the sector. The main characteristics of the real data are described below. More details of the real data instances can be found in Vanzela [35].

- Problem size: $F=8$ products; $T=4$ periods (weeks); $P=72$ pieces grouped into $e=4$ thickness $\left(o^{e}=9 \mathrm{~mm}, 15 \mathrm{~mm}, 18 \mathrm{~mm}, 25 \mathrm{~mm}\right.$ for $e=1, \ldots, 4$ respectively).

- Table 1 shows the production costs $\left(c_{f}\right)$ for each product (the plates costs are not included).

- The inventory costs for products $\left(h_{f}\right)$ shown in Table 1 are obtained based on the return rate considering the value $c_{f}$ applied on the financial market.

- Initial inventory of products $\left(I_{f 0}\right): 60 \%$ of total demand of product $f$.

- Percentage of minimum inventory levels (ts): $60 \%$ of the demand for a given period.

- Plates dimension $(L \times W):(2750 \mathrm{~mm} \times 1850 \mathrm{~mm})$.

- Plates Costs $\left(c o^{e}\right)$ : the costs were determined according to market prices as 45.79, 65.63, 36.37, and 97.17 for $e=1, \ldots, 4$ respectively.

- Pieces Costs $\left(c p_{p}^{e}\right)$ : computed as $c p_{p}^{e}=\left(\frac{l_{p}^{e} \cdot w_{p}^{e}}{L \cdot W}\right) \cdot c o^{e}$. This cost is also used to compute the inventory costs of pieces $\hat{h}_{p}^{e}$.

- Inventory costs of pieces $\left(\hat{h}_{p}^{e}\right)$ : based on the return rate considering

Table 1

Production and inventory costs of products.

\begin{tabular}{lll}
\hline Product & Production cost $\left(c_{f}\right)$ & Inventory cost $\left(h_{f}\right)$ \\
\hline (1) MC & 42.00 & 0.21 \\
(2) DT & 75.00 & 0.39 \\
(3) W1 & 175.00 & 0.84 \\
(4) W2 & 152.00 & 0.70 \\
(5) W3 & 113.00 & 0.57 \\
(6) W4 & 188.00 & 0.85 \\
(7) W5 & 141.00 & 0.70 \\
(8) W6 & 175.00 & 0.84 \\
\hline
\end{tabular}

the value $c p_{p}^{e}$ applied on the financial market.

- Initial inventory of pieces $\left(I P_{p 0}^{e}\right)$ : zero.

- Saw height (S): $105 \mathrm{~mm}$.

- Estimated cutting capacity for a given period (saw cycles) $\left(C_{t}\right)$ : In order to calculate $\left(C_{t}\right)$ we observed that the velocity of the saw is on average $8.5 \mathrm{~min}$ per cycle. Considering that each week has 5 working days, and that a single day has 8-h shift, we get that the saw capacity in each period $t$ is $C_{t}=340$ saw cycles.

- Capacity adjustment $(t x): 0.85$.

- Demands for product $\left(D_{f t}\right)$ are shown in Table 2. For the sake of simplicity we only show the first instance for each month. Observe that for each month we have 4 periods representing the 4 weeks.

- Product structure: Table A1 (Appendix) show the number of pieces of $15 \mathrm{~mm}$ that compose each product.

\subsection{Computational results - Part I}

In this section, the computational results obtained with the mathematical models described in Section 4 are presented. Basically, three models or combination of models, are analyzed: the first one, $L S P$ $+C S P$, is typically used in the industry and solves sequentially the non capacitated lot sizing problem followed by the cutting stock problem; the second one, $C L S P+C S P$, requires an estimation of the capacity and also simulate the industry decision process by solving sequentially the capacitated lot sizing problem followed by the cutting stock problem; the third one, the ILSCSP, models the proposal of taking an integrated decision.

\subsubsection{Lot sizing results}

We begin by analyzing the cost associated with the solution obtained by each model considering only the lot sizing costs (objective function (11)). As the production costs are constant over the periods and the demand must be met, there is no reason to compare the production cost related to the integrated decision (ILSCSP) and the lot sizing ( $L S P$ and $C L S P$ ) decisions, because they will be the same. The difference appears in the Inventory Costs related to the products which are shown in Table 3 with the best results marked in bold. It can be seen that the LSP model obtains better results than the CLSP and ILSCSP for all but two instances, instances 1 and 4, for which the value are the same for all models. These results were expected since the $L S P$ has only to meet the demand and satisfy the safety stock. On the other hand, the models that consider capacity constraint (the CLSP+CSP and the $I L S C S P$ ) are forced to keep in stock a greater number of final products in order to meet the demand without exceeding the capacity of the cutting machine. Note that the ILSCSP model gives the second best results (in 12 out of 15 instances when compared only to the CLSP $+C S P$ ), which shows that the integrated approach has a better overview 
Table 2

Weekly demand for the first instances of March (low demand), August (medium demand) and November (high demand).

\begin{tabular}{|c|c|c|c|c|c|}
\hline \multicolumn{6}{|c|}{ March (low demand) } \\
\hline \multicolumn{6}{|c|}{ Instance 1} \\
\hline \multirow[t]{2}{*}{ Product } & \multicolumn{4}{|c|}{ Periods } & \multirow[t]{2}{*}{ SumF } \\
\hline & 1 & 2 & 3 & 4 & \\
\hline (1) $\mathrm{MC}$ & 40 & 40 & 40 & 40 & 160 \\
\hline (2) DT & & 120 & & & 120 \\
\hline (3) $\mathrm{W1}$ & & 80 & 80 & & 160 \\
\hline (4) W2 & & & & 70 & 70 \\
\hline (5) W3 & & 25 & 25 & & 50 \\
\hline (6) $\mathrm{W4}$ & 115 & 115 & & & 230 \\
\hline (7) W5 & & & 160 & & 160 \\
\hline (8) W6 & 170 & 170 & & & 340 \\
\hline SumT & 325 & 550 & 305 & 110 & 1290 \\
\hline$\%$ Prod & 25.19 & 42.64 & 23.64 & 8.53 & 100.00 \\
\hline
\end{tabular}

August (medium demand)

\begin{tabular}{|c|c|c|c|c|c|}
\hline \multicolumn{6}{|c|}{ Instance 6} \\
\hline \multirow[t]{2}{*}{ Product } & \multicolumn{4}{|c|}{ Periods } & \multirow[t]{2}{*}{ SumF } \\
\hline & 1 & 2 & 3 & 4 & \\
\hline (1) $\mathrm{MC}$ & 60 & & 40 & 100 & 200 \\
\hline (2) DT & & 85 & 100 & & 185 \\
\hline (3) $\mathrm{W} 1$ & & 190 & & & 190 \\
\hline (4) W2 & & & 66 & & 66 \\
\hline (5) W3 & 33 & & & 33 & 66 \\
\hline (6) W4 & & 100 & & 150 & 250 \\
\hline (7) W5 & 50 & & & 50 & 100 \\
\hline (8) W6 & 200 & & & 240 & 440 \\
\hline SumT & 343 & 375 & 206 & 573 & 1497 \\
\hline \%Prod & 22.91 & 25.05 & 13.76 & 38.28 & 100.00 \\
\hline
\end{tabular}

November (high demand)

\begin{tabular}{|c|c|c|c|c|c|}
\hline \multicolumn{6}{|c|}{ Instance 11} \\
\hline \multirow[t]{2}{*}{ Product } & \multicolumn{4}{|c|}{ Periods } & \multirow[t]{2}{*}{ SumF } \\
\hline & 1 & 2 & 3 & 4 & \\
\hline (1) $\mathrm{MC}$ & & & & 310 & 310 \\
\hline (2) DT & 70 & 50 & 50 & & 170 \\
\hline (3) W1 & 50 & & 100 & 100 & 250 \\
\hline (4) W2 & & 105 & & & 105 \\
\hline (5) $\mathrm{W3}$ & & & & & 0 \\
\hline (6) $\mathrm{W} 4$ & & 200 & 100 & 120 & 420 \\
\hline (7) W5 & 45 & & 100 & & 145 \\
\hline (8) W6 & 100 & 200 & 120 & 100 & 520 \\
\hline SumT & 265 & 555 & 470 & 630 & 1920 \\
\hline \% Prod & 13.80 & 28.91 & 24.48 & 32.81 & 100.00 \\
\hline
\end{tabular}

of the available capacity then the estimation given in CLSP.

\subsubsection{Cutting stock results}

The following considers the results obtained with the $L S P+C S P$, $C L S P+C S P$ and ILSCSP models for the costs regarding to the multiperiod cutting stock problem. Some factors can influence the solution in each model. The possibility of storing pieces and the characteristics of each instance can affect the solutions of the models. To analyze this influence, Table 4 shows the raw material costs and the total inventory costs of pieces (over all the four periods) obtained for each model, with the best results marked in bold. The models CLSP+CSP and ILSCSP resulted in better solutions than the model $L S P+C S P$. Due to the capacity constraints of the models $C L S P+C S P$ and $I L S C S P$, some lots of
Table 3

Inventory costs of final products.

\begin{tabular}{llll}
\hline \multicolumn{2}{l}{ Inventory costs (\$) } & & \\
\hline Inst & LSP & CLSP & ILSCSP \\
\hline 1 & 1566.37 & 1566.37 & 1566.37 \\
2 & $\mathbf{2 0 0 4 . 5 2}$ & 2140.62 & 2149.98 \\
3 & $\mathbf{1 4 5 2 . 2 8}$ & 1585.05 & 1576.41 \\
4 & 1982.80 & 1982.80 & 1982.80 \\
5 & $\mathbf{1 5 7 5 . 7 4}$ & 1613.73 & 1595.43 \\
& & & \\
6 & $\mathbf{1 7 2 4 . 1 6}$ & 1967.78 & 1909.06 \\
7 & $\mathbf{1 6 9 8 . 6 1}$ & 1802.89 & 1825.22 \\
8 & $\mathbf{1 5 4 8 . 2 7}$ & 1909.61 & 1824.83 \\
9 & $\mathbf{1 7 6 5 . 0 4}$ & 1867.91 & 1656.07 \\
10 & $\mathbf{1 5 4 1 . 8 9}$ & 1745.22 & \\
& & & 2649.07 \\
11 & $\mathbf{2 1 0 4 . 1 2}$ & 2693.19 & 2911.92 \\
12 & $\mathbf{2 3 1 5 . 2 3}$ & 3075.60 & 2611.55 \\
13 & $\mathbf{2 0 5 7 . 6 7}$ & 2700.09 & 2542.85 \\
14 & $\mathbf{1 8 3 6 . 4 8}$ & 2544.23 & 2901.50 \\
15 & $\mathbf{2 0 8 8 . 0 9}$ & 3035.82 & \\
\hline
\end{tabular}

products were brought forward which allowed better combinations of pieces and consequently the generation of more efficient cutting patterns without bringing forward the cut of too many pieces. On the other hand, the model $L S P+C S P$ brought forward the cut of some pieces in order to generate efficient cutting patterns, this resulted in an increase in the pieces inventory costs (for all but one instance). Moreover, the total number of plates cut for the $L S P+C S P$ instances is higher than the total number of plates necessary for the instances of the other two models. See the raw material costs in Table 4, which are higher for all but two instances.

Table 5 presents the costs from the cutting stock problem (objective function (17)). As a consequence of the results shown in Table 4, in general, the $C L S P+C S P$ and ILSCSP models perform better than the $L S P+C S P$ model. Observe that these results are contrary to the results regarding the lot sizing costs, the $C L S P+C S P$ and the $I L S C S P$ models together gave better results for 13 out of the 15 instances.

\subsubsection{Lot sizing and cutting stock results}

Table 6 shows the total cost values for each instance of the ILSCSP, $L S P+C S P$, and $C L S P+C S P$ models (objective function (1) or (11) plus (17)). These results show that there is a reduction in the total cost for almost all the instances (13 out of 15) when considering the capacity constraint in the production planning (the solutions to the ILSCSP and $C L S P+C S P$ models). This improvement is mainly due to the estimation given to the capacity constraint, which generates a planning of products that can reduce the costs of the cutting stock problem. The reduction of the cutting cost is due to the earlier production of some pieces that will soon be used to produce some products and therefore results in better solutions to the cutting stock problem as seen in the previous tables.

Comparing the results obtained by $C L S P+C S P$ and $I L S C S P$ we can see that the integrated approach does not always provide the best solution. This allows us to conclude that, for these instances, a good estimation of the cutting machine capacity in the lot sizing level can be as effective as the integrated approach. We have not found this kind of behavior for the scenarios described in the literature. Since the three solution approaches are heuristic methods, the column generation procedure is halted after a pre-defined amount of time and an optimization package is used to find a feasible integer solution, it is acceptable to have this kind of results. The results presented in Section 6.3 allow a better understanding of the behavior of these solution approaches and the impact of the costs in the associated decisions. 
Table 4

Raw-material cost and inventory costs of pieces.

\begin{tabular}{|c|c|c|c|c|c|c|}
\hline \multirow[t]{2}{*}{ Inst } & \multicolumn{3}{|c|}{ Raw-material cost $(\$)$} & \multicolumn{3}{|c|}{ Inventory cost of pieces $(\$)$} \\
\hline & $\mathbf{L S P}+\mathbf{C S P}$ & CLSP+CSP & ILSCSP & $\mathbf{L S P}+\mathbf{C S P}$ & CLSP+CSP & ILSCSP \\
\hline 1 & $242,613.00$ & $242,547.00$ & 241,574.85 & 30.13 & 37.91 & 35.87 \\
\hline 2 & $243,058.00$ & $244,596.00$ & 241,875.01 & 253.84 & 155.70 & 104.63 \\
\hline 3 & $242,378.00$ & $235,621.00$ & $245,466.79$ & 275.50 & 165.81 & 106.50 \\
\hline 4 & $231,037.00$ & $231,635.00$ & $229,935.41$ & 96.26 & 72.38 & 95.30 \\
\hline 5 & $238,667.00$ & $240,109.00$ & $237,688.51$ & 102.12 & 99.42 & 89.68 \\
\hline 6 & $268,618.00$ & $265,030.00$ & $265,385.11$ & 327.61 & 107.74 & 121.53 \\
\hline 7 & $279,239.00$ & $272,860.00$ & $279,524.04$ & 181.92 & 176.24 & 143.54 \\
\hline 8 & $279,295.00$ & 275,829.00 & $279,258.73$ & 546.17 & 205.08 & 231.65 \\
\hline 9 & $267,463.00$ & $268,495.00$ & $258,873.88$ & 178.88 & 140.79 & 109.60 \\
\hline 10 & $267,740.00$ & $269,953.00$ & $267,174.90$ & 333.75 & 155.26 & 201.82 \\
\hline 11 & $342,065.00$ & $363,572.00$ & $362,031.59$ & 862.00 & 425.31 & 335.63 \\
\hline 12 & $351,825.00$ & $339,963.00$ & $341,956.82$ & 1161.06 & 317.52 & 382.19 \\
\hline 13 & $360,878.00$ & $354,469.00$ & $359,316.39$ & 924.16 & 343.73 & 407.19 \\
\hline 14 & $363,107.00$ & $361,155.00$ & $369,011.13$ & 1112.07 & 277.33 & 265.03 \\
\hline 15 & $341,006.00$ & $360,464.00$ & $360,932.69$ & 1409.60 & 328.78 & 427.15 \\
\hline
\end{tabular}

Table 5

Cutting stock costs.

\begin{tabular}{llll}
\hline \multicolumn{2}{l}{ Cutting stock cost (\$) } & & \\
\hline Ins & LSP+CSP & CLSP+CSP & ILSCSP \\
\hline 1 & $242,643.13$ & $242,584.91$ & $\mathbf{2 4 1 , 6 1 0 . 7 2}$ \\
2 & $243,311.84$ & $244,751.70$ & $\mathbf{2 4 1 , 9 7 9 . 6 5}$ \\
3 & $242,653.50$ & $\mathbf{2 3 5 , 7 8 6 . 8 1}$ & $245,573.28$ \\
4 & $231,133.26$ & $231,707.38$ & $\mathbf{2 3 0 , 0 3 0 . 7 1}$ \\
5 & $238,769.12$ & $240,208.42$ & $\mathbf{2 3 7 , 7 7 8 . 1 9}$ \\
& & & \\
6 & $268,945.61$ & $\mathbf{2 6 5 , 1 3 7 . 7 4}$ & $265,506.65$ \\
7 & $279,420.92$ & $\mathbf{2 7 3 , 0 3 6 . 2 4}$ & $279,667.58$ \\
8 & $279,841.17$ & $\mathbf{2 7 6 , 0 3 4 . 0 8}$ & $279,490.38$ \\
9 & $267,641.88$ & $268,635.79$ & $\mathbf{2 5 8 , 9 8 3 . 4 8}$ \\
10 & $268,073.75$ & $270,108.26$ & $\mathbf{2 6 7 , 3 7 6 . 7 2}$ \\
& & & \\
11 & $\mathbf{3 4 2 , 9 2 7 . 0 0}$ & $363,997.31$ & $362,367.22$ \\
12 & $352,986.06$ & $\mathbf{3 4 0 , 2 8 0 . 5 2}$ & $342,339.01$ \\
13 & $361,802.16$ & $\mathbf{3 5 4 , 8 1 2 . 7 3}$ & $359,723.58$ \\
14 & $364,219.07$ & $\mathbf{3 6 1}, \mathbf{4 3 2 . 3 3}$ & $369,276.16$ \\
15 & $\mathbf{3 4 2 , 4 1 5 . 6 0}$ & $360,792.78$ & $361,359.84$ \\
\hline & & & \\
\hline
\end{tabular}

Table 6

Total costs.

\begin{tabular}{llll}
\hline \multicolumn{2}{l}{ Total costs (\$) } & & \\
\hline Ins & LSP+CSP & CLSP+CSP & ILSCSP \\
\hline 1 & $430,779.50$ & $430,721.28$ & $\mathbf{4 2 9 , 7 4 7 . 0 9}$ \\
2 & $430,626.36$ & $432,202.31$ & $\mathbf{4 2 9 , 4 3 9 . 6 2}$ \\
3 & $429,415.78$ & $\mathbf{4 2 2 , 6 8 1 . 8 5}$ & $432,459.70$ \\
4 & $418,426.05$ & $419,000.17$ & $\mathbf{4 1 7 , 3 2 3 . 5 1}$ \\
5 & $425,654.86$ & $427,132.15$ & $\mathbf{4 2 4 , 6 8 3 . 6 2}$ \\
& & & \\
6 & $481,890.77$ & $\mathbf{4 7 8 , 3 2 6 . 5 2}$ & $478,636.71$ \\
7 & $494,440.54$ & $\mathbf{4 8 8 , 1 6 0 . 1 4}$ & $494,742.79$ \\
8 & $492,610.44$ & $\mathbf{4 8 9 , 1 6 4 . 6 9}$ & $492,536.38$ \\
9 & $480,627.92$ & $481,724.71$ & $\mathbf{4 7 2 , 0 2 9 . 3 1}$ \\
10 & $476,799.04$ & $479,036.88$ & $\mathbf{4 7 6 , 2 1 6 . 1 9}$ \\
& & & \\
11 & $\mathbf{6 2 0 , 9 1 6 . 1 1}$ & $642,575.50$ & $640,901.29$ \\
12 & $631,186.29$ & $\mathbf{6 1 9 , 2 4 1 . 1 2}$ & $621,135.93$ \\
13 & $639,744.83$ & $\mathbf{6 3 3 , 3 9 7 . 8 2}$ & $638,220.13$ \\
14 & $641,940.55$ & $\mathbf{6 3 9 , 8 6 1 . 5 7}$ & $647,704.01$ \\
15 & $\mathbf{6 2 0 , 3 8 8 . 6 9}$ & $639,713.60$ & $640,146.34$ \\
\hline & & & \\
\hline
\end{tabular}

\subsection{Computational results - Part II}

In this section, two further tests were performed in order to evaluate the impact of the costs in the proposed approaches. The first one involves variations in the inventory costs of pieces and the second analysis considers variations in the costs of plates and in the inventory costs of final products.

\subsubsection{Varying the inventory costs of pieces}

The costs associated with the inventory of pieces in the 15 instances used in the tests described in Section 6.2 were based on the return rate considering the value of the pieces costs applied on the financial market. However, it might be important to increase these costs by considering the effort necessary to manage these pieces in stock. In what follows, we study the behavior of the solutions approaches when the inventory costs of a piece $\left(h_{p}^{e}\right)$ is increased by a factor of 10,50 and 100.

Table 7 shows the total inventory costs of pieces for each instance, considering the three different variations $\left(10 \times h_{p}^{e}, 50 \times h_{p}^{e}\right.$ and $100 \times h_{p}^{e}$ ) for each model. In this analysis it is possible to see the increase in the inventory costs of pieces whereas the parameter values increase, but this increase is much smaller for the integrated approach ILSCSP. Analyzing the quantity of pieces in stock, we observed that, when the factor 100 is considered, this quantity is on average up to $67.7 \%$ and $78.6 \%$ reduced considering $C L S P+C S P$ and $I L S C S P$ models, respectively, when compared with the $L S P+C S P$ model. The large difference in the quantity of pieces in stock for the instances of the ILSCSP model is due to its feature that takes into account the inventory costs of pieces simultaneously with the other decisions costs. As the inventory costs of pieces increase there is a tendency to increase the inventory of final products in order to obtain a better overall solution. Hence, by anticipating the final products it is possible to obtain good combinations of items and cutting patterns which allows the reduction of the total costs of plates without the need to anticipate pieces production and thus reducing the total inventory costs of pieces. The other two models do not have this feature, and an attempt to minimize the inventory costs of final products is done when taking the lot sizing decision. Afterwards, on the multi-period cutting stock decision, there is a tendency to anticipate pieces in order to have better combinations on producing the cutting patterns. Obviously this reduces the costs of plates, but increases the inventory costs of pieces.

Table 8 shows the difference (in percentage) of the total costs of the $C L S P+C S P$ and $I L S C S P$ models compared with the $L S P+C S P$ model considering the 3 variations of the inventory costs of pieces. The values 
Table 7

Varying inventory costs of pieces.

\begin{tabular}{|c|c|c|c|c|c|c|c|c|c|}
\hline \multicolumn{10}{|c|}{ Costs of pieces inventory } \\
\hline \multirow[t]{2}{*}{ Ins } & \multicolumn{3}{|l|}{$\mathbf{L S P}+\mathbf{C S P}$} & \multicolumn{3}{|c|}{ CLSP+CSP } & \multicolumn{3}{|l|}{ ILSCSP } \\
\hline & $10 \times \hat{h}_{p}^{e}$ & $50 \times \hat{h}_{p}^{e}$ & $100 \times \hat{h}_{p}^{e}$ & $10 \times \widehat{h}_{p}^{e}$ & $50 \times \hat{h}_{p}^{e}$ & $100 \times \widehat{h}_{p}^{e}$ & $10 \times \widehat{h}_{p}^{e}$ & $50 \times \hat{h}_{p}^{e}$ & $100 \times \hat{h}_{p}^{e}$ \\
\hline 1 & 267.45 & 1207.43 & 1637.34 & 267.45 & 1362.56 & 1495.09 & 409.87 & 987.17 & 1928.10 \\
\hline 2 & 2547.96 & $12,148.83$ & $21,629.35$ & 684.88 & 2434.61 & 4994.72 & 366.09 & 1530.16 & 2417.88 \\
\hline 3 & 2260.74 & 8948.94 & $17,895.32$ & 905.12 & 2826.90 & 2791.12 & 577.20 & 1214.25 & 2159.45 \\
\hline 4 & 286.57 & 681.69 & 1336.66 & 445.67 & 1193.77 & 1237.82 & 270.95 & 1133.66 & 1385.97 \\
\hline 5 & 1093.02 & 3403.05 & 6588.78 & 1073.98 & 2098.28 & 4393.24 & 699.43 & 2069.49 & 3886.38 \\
\hline 6 & 3250.66 & $14,593.79$ & $28,107.57$ & 648.45 & 3569.12 & 2644.91 & 632.10 & 1760.64 & 3824.92 \\
\hline 7 & 2601.82 & 8708.72 & $12,197.20$ & 876.98 & 2172.70 & 8568.81 & 705.61 & 2915.34 & 5794.96 \\
\hline 8 & 4978.39 & $25,153.90$ & $49,648.37$ & 1342.31 & 6714.42 & 8407.02 & 974.47 & 5526.55 & 3727.37 \\
\hline 9 & 1470.46 & 7776.54 & $13,647.60$ & 1102.00 & 1898.36 & 2413.66 & 646.27 & 1354.78 & 2612.71 \\
\hline 10 & 2937.28 & $14,282.85$ & $27,209.89$ & 1149.77 & 3369.38 & 7885.44 & 1238.17 & 2965.76 & 3501.05 \\
\hline 11 & 8663.20 & $41,625.07$ & $79,602.22$ & 2668.31 & $11,744.94$ & $24,407.14$ & 1205.94 & 3547.81 & 7259.96 \\
\hline 12 & $10,190.08$ & $50,319.76$ & $99,253.49$ & 1729.19 & 5452.17 & 4906.95 & 1082.46 & 4748.83 & 6696.40 \\
\hline 13 & 9449.54 & $43,085.95$ & $83,831.88$ & 2135.35 & 6179.99 & 4906.95 & 1186.53 & 4020.59 & 4727.31 \\
\hline 14 & $10,657.36$ & $52,944.56$ & $91,395.27$ & 3085.81 & 7392.32 & 8153.27 & 1476.92 & 6060.84 & 9056.85 \\
\hline 15 & $12,829.72$ & $65,980.41$ & $136,410.00$ & 2540.14 & $11,685.74$ & $25,530.96$ & 1723.17 & 188.79 & 7150.06 \\
\hline
\end{tabular}

Table 8

Total costs difference.

\begin{tabular}{|c|c|c|c|c|c|c|c|c|c|}
\hline \multicolumn{10}{|c|}{ Difference in total cost } \\
\hline \multirow[t]{2}{*}{ Ins } & \multicolumn{3}{|c|}{$\mathbf{L S P}+\mathbf{C S P}$} & \multicolumn{3}{|c|}{ CLSP+CSP } & \multicolumn{3}{|l|}{ ILSCSP } \\
\hline & $10 \times \hat{h}_{p}^{e}$ & $50 \times \hat{h}_{p}^{e}$ & $100 \times \hat{h}_{p}^{e}$ & $10 \times \hat{h}_{p}^{e}$ & $50 \times \hat{h}_{p}^{e}$ & $100 \times \hat{h}_{p}^{e}$ & $10 \times \hat{h}_{p}^{e}$ & $50 \times \hat{h}_{p}^{e}$ & $100 \times \hat{h}_{p}^{e}$ \\
\hline 1 & 100 & 100 & 100 & 0.000 & 0.372 & -0.492 & -2.434 & 1.809 & 0.361 \\
\hline 2 & 100 & 100 & 100 & 0.099 & 1.299 & 3.140 & 0.953 & 2.143 & 4.004 \\
\hline 3 & 100 & 100 & 100 & 0.507 & 2.729 & 4.941 & -1.247 & 4.825 & 2.916 \\
\hline 4 & 100 & 100 & 100 & 0.793 & -0.148 & 0.073 & -0.886 & 1.255 & 0.273 \\
\hline 5 & 100 & 100 & 100 & -0.085 & -0.353 & -0.979 & -0.216 & -0.256 & -2.285 \\
\hline 6 & 100 & 100 & 100 & 0.767 & 2.142 & 5.278 & 0.969 & 2.297 & 5.603 \\
\hline 7 & 100 & 100 & 100 & 1.060 & 1.601 & 0.559 & -2.078 & -1.269 & -0.694 \\
\hline 8 & 100 & 100 & 100 & 1.302 & 3.554 & 7.883 & -0.190 & 3.632 & 8.321 \\
\hline 9 & 100 & 100 & 100 & -0.296 & 0.964 & 1.983 & 1.045 & 0.904 & 1.335 \\
\hline 10 & 100 & 100 & 100 & 0.244 & 1.853 & 3.466 & 0.621 & 1.945 & 6.204 \\
\hline 11 & 100 & 100 & 100 & -1.564 & 1.652 & 5.234 & -0.694 & 2.733 & 7.143 \\
\hline 12 & 100 & 100 & 100 & -1.638 & 5.333 & 12.111 & -2.282 & 2.753 & 8.995 \\
\hline 13 & 100 & 100 & 100 & 0.613 & 4.078 & 12.603 & 0.331 & 4.476 & 9.825 \\
\hline 14 & 100 & 100 & 100 & 2.797 & 6.762 & 10.656 & 0.747 & 8.281 & 7.878 \\
\hline 15 & 100 & 100 & 100 & -1.368 & 5.505 & 14.195 & -1.624 & 6.526 & 15.579 \\
\hline
\end{tabular}

Table 9

Classes.

\begin{tabular}{lll}
\hline Classes & $\mathrm{co}^{e}$ & $h_{f}$ \\
\hline 1 & $\mathrm{~L}$ & $\mathrm{~L}$ \\
2 & $\mathrm{~L}$ & $\mathrm{H}$ \\
3 & $\mathrm{H}$ & $\mathrm{L}$ \\
4 & $\mathrm{H}$ & $\mathrm{H}$ \\
\hline
\end{tabular}

associated to the $L S P+C S P$ model represents $100 \%$ of the total costs and for the other approaches the values correspond to the percentage of gains (positive values) or losses (negative values), when compared to the respective $L S P+C S P$ values. The results shows that as the inventory costs of pieces increase, the gains for both models also increase, specially for instances with high demand (November). Moreover, the gains obtained by the ILSCSP model is substantially higher than the gains obtained by the $C L S P+C S P$ model. Therefore, it is possible to affirm that the integrated approach can handle more effectively the
Table 10

Total costs: Improvements.

\begin{tabular}{lllll}
\hline Month & Class & LSP+CSP & CLSP+CSP & ILSCSP \\
\hline March & 1 & 100 & 0.6 & -0.05 \\
& 2 & 100 & -0.22 & -0.58 \\
& 3 & 100 & 0.72 & 0.03 \\
& 4 & 100 & -0.03 & -0.53 \\
August & 1 & 100 & 2.69 & 3.75 \\
& 2 & 100 & 2.76 & 2.63 \\
& 3 & 100 & 2.33 & 3.62 \\
& 4 & 100 & 2.46 & 3.52 \\
November & 1 & 100 & 2.65 & 29.4 \\
& 2 & 100 & 3.3 & 29.07 \\
& 3 & 100 & 1.35 & 28.56 \\
& 4 & 100 & 1.62 & 28.79 \\
\hline
\end{tabular}


Table A1

Product structure - thickness $15 \mathrm{~mm}$.

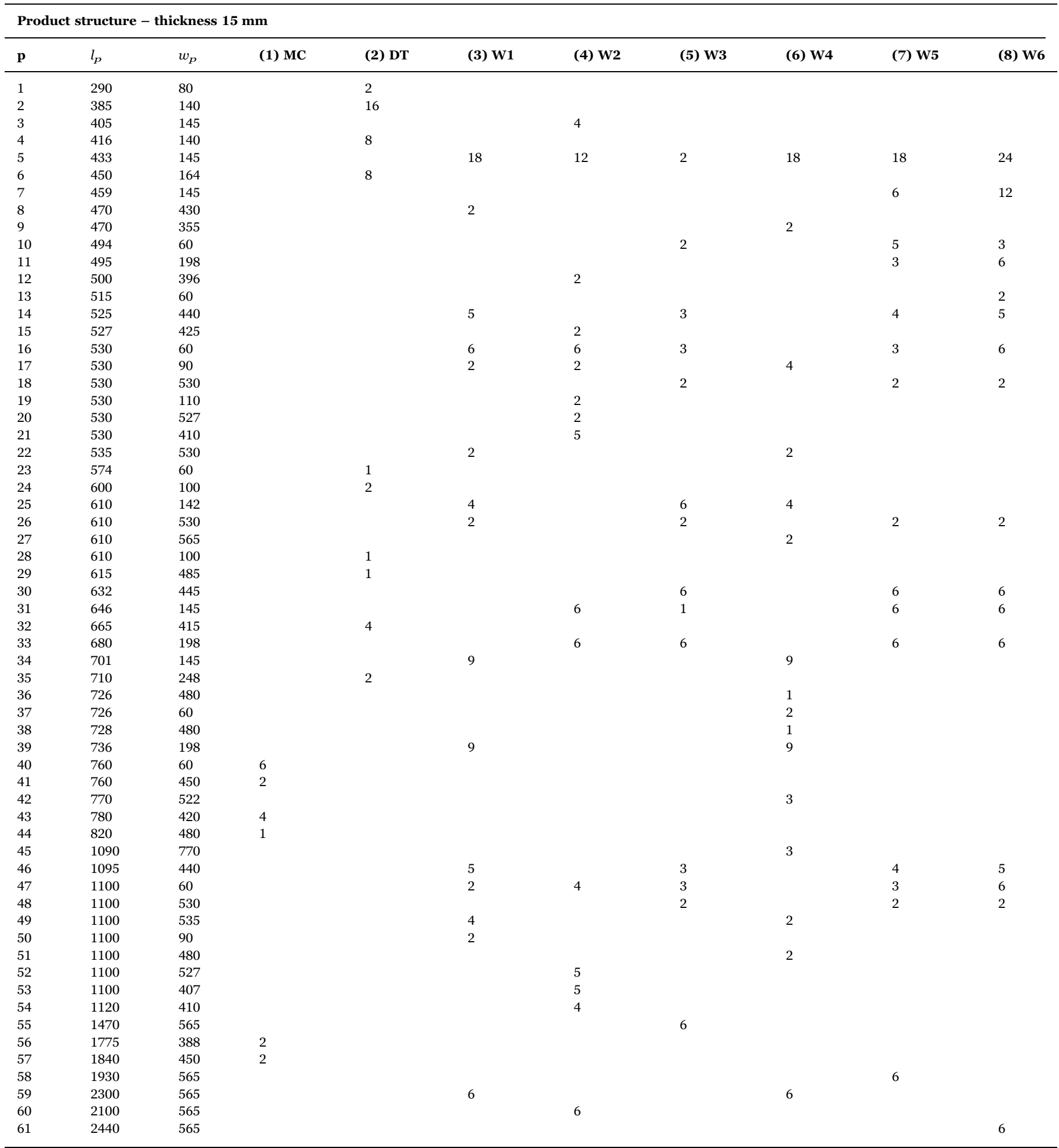

decisions when costs for managing the inventory of pieces are taken into account.

6.3.2. Varying the costs of plates and the inventory costs of final products

Based on the practical data, described in Section 6.1, we vary the costs of plate $\left(\mathrm{co}^{e}\right)$ and inventory costs of final products $\left(h_{f}\right)$ in order to estimate the impact of these variations in the objective function of the proposed approaches. The changes in the costs are between $10 \%$ and $30 \%$ compared with the original value. The new sets of costs are generated in the intervals [cost - cost $\times 0.3$, cost - cost $\times 0.1]$ for low costs (L) and $[\cos t+\cos t \times 0.1, \cos t+\cos t \times 0.3]$ for high costs $(H)$. The parameter cost refers to the two analyzed costs $\left(c o^{e}\right.$ and $\left.h_{f}\right)$. The inventory costs of pieces $\left(\widehat{h}_{p}^{e}\right)$ are fixed to the values of the second variation considered in Section 6.3.1 (i.e. 50 times the original costs). The possible combinations for low $(L)$ costs and high $(H)$ costs form 4 
classes of instances that are presented in Table 9.

Considering the data sets from Section 6.1 we took the first instance for each month (March, August and November) which represent instances with Low, Medium and High demand, respectively. Observe that these are exactly the three instances for which the demands are presented in Table 2. Based on each one of these 3 instances we randomly generated five new instances varying the costs according to the interval previously described and considering 4 classes from Table 9. Therefore, a total of 3 (practical instances) $\times 5$ (random instances) $\times 4$ (classes) $=60$ new instances were generated.

Table 10 shows, for each class, the average difference (in percentage) of the total costs to the CLSP+CSP and ILSCSP models when compared with the $L S P+C S P$ model. Considering the month with low demand, the three models are almost equivalent. However, when the level of demand increase (August and November), the integrated approach provides better results for all the classes and the gains are even greater for the instances with high demands reaching a gain of $29.4 \%$ compared to the $L S P+C S P$ model. So, it is possible to conclude that the integrated approach can handle more effectively the decisions in high demand sceneries, i.e., when the capacity utilization is more intensive. Considering the four different classes which represent different costs scenarios, it is possible to see that for the majority of the cases the impact in the gains is slightly reduced as the costs of plates increase (classes 3 and 4). It is not possible to draw a conclusion about the variation of the inventory costs of final products.

\section{Conclusions}

A mathematical model was proposed and implemented to analyze the main decisions of the production process of small scale furniture factories. The integrated model (ILSCSP) was proposed to capture the interdependencies of the lot sizing and the cutting stock decisions and thus promote a new approach to the decision making process. To simulate the modus operandi of Factory L, the ILSCSP model was decomposed in two models: a Lot sizing model (capacitated-CLSP and non capacitated-LSP) and a multi-period cutting stock model (CSP).
The tests to validate the models were based on the product list of Factory L and on parameters taken from the market. A column generation technique was used to solve the Restricted Master Problem related to the ILSCSP and CSP models. Good overall results were obtained when comparing the ILSCSP solutions to the solutions of the approach of sequentially solving the non capacitated model $L S P$ $+C S P$. Compared to the capacitated model $C L S P+C S P$, the results of the integrated model ILSCSP were competitive with the advantage that it is not necessary to estimate the used capacity, which is a difficult task in practice.

Further computational tests were executed in order to evaluated the impact of the different costs in the objective function for each approach. At first, three variations in the inventory costs of pieces were considered by taking into account the effort necessary to handle and administrate the pieces in stock. Then a variation in the costs of plates and in the inventory costs of final products are studied. The results showed that, in general, the integrated approach is better, mainly when the inventory costs of pieces are high and/or the demands are high. The variations on the costs of plates and inventory costs of final products do not have a strong impact on the differences among the three models.

We conclude from the computational study that the solution obtained can be put into practice, the models can support the main decisions taken and can bring improvements to the factory's production planning decisions.

\section{Acknowledgments}

This research was partially funded by the Brazilian agencies: Conselho Nacional de Desenvolvimento Científico e Tecnológico CNPq, Coordenação de Aperfeiçoamento de Pessoal de Nível Superior - CAPES and Fundação de Amparo a Pesquisa do Estado de São Paulo FAPESP (2012/20631-2, 2014/17273-2 and 2013/07375-0) The authors are grateful to Factory $\mathrm{L}$ for providing the data used in the computational study. Thanks are also due to the anonymous referees for their constructive suggestions.

\section{Appendix A. Products structure}

See Table A1.

\section{References}

[1] Alem D, Jr., Morabito R. Production planning in furniture settings via robust optimization. Comput Oper Res 2012;39:139-50.

[2] Alem D, Jr., Morabito R. Risk-averse two-stage stochastic programs in furniture plants. OR Spectr 2013;35:773-806.

[3] Arbib C, Marinelli F. Integrating process optimization and inventory planning in cutting-stock with skiving option: an optimization model and its application. Eur J Oper Res 2005; 163:617-30.

[4] Cui Y, Zhong C, Yao Y. Pattern-set generation algorithm for the one-dimensional cutting stock problem with setup cost. Eur J Oper Res 2015;243:540-6.

[5] Dyckhoff H. A new linear programming approach to the cutting stock problem. Oper Res 1981;29:1092-104.

[6] Farley AA. Mathematical programming models for cutting-stock problems in the clothing industry. J Oper Res Soc 1988;39:41-53.

[7] Fico. Fico Xpress 7.2: X-Press Mosel Language Reference Manual. (〈http://www. fico.com/account/resourcelookup.aspx?theID=725〉Access: 24 June 2015); 2013.

[8] FIESP. Fundação das Indústrias do Estado de São Paulo. Análise setorial de mercado: Setor de móveis. Technical report. São Paulo-SP, Brazil; 2009.

[9] Gilmore PC, Gomory RE. A linear programming approach to the cutting-stock problem. Oper Res 1961:9:849-59.

[10] Gilmore PC, Gomory RE. A linear programming approach to the cutting-stock problem - part ii. Oper Res 1963;11:863-88.

[11] Gilmore PC, Gomory RE. Multistage cutting stock problems of two and more dimensional. Oper Res 1965;14:1045-74.
[12] Gramani MCN, França PM. The combined cutting stock and lot sizing problem in industrial process. Eur J Oper Res 2006;74:509-21.

[13] Gramani MCN, França PM, Arenales MN. A Lagrangian relaxation approach to a coupled lot-sizing and cutting stock problem. Int J Prod Econ 2009;119:219-27.

[14] Gramani MCN, França PM, Arenales MN. A linear optimization approach to the combined production planning model. J Frankl Inst 2011;348:1523-36.

[15] Haessler RW. A heuristic programming solution to a nonlinear cutting stock problem. Manage Sci 1971;17:793-802.

[16] Hendry LC, Fok KK, Shek KW. A cutting stock and scheduling problem in the copper industry. J Res Dev 1996;16:553-64.

[17] Henn S, Wäscher G. Extensions of cutting stock problems: setups. Pesqui Oper 2013;33:133-62.

[18] Jans R, Degraeve Z. Modeling industrial lot sizing problems: a review. Int J Prod Res 2008;46:1619-43.

[19] Morabito R, Arenales M. Optimising the cutting of stock plates in a furniture company. Int J Prod Res 2000;38:2725-42.

[20] Morabito R, Arenales MN, Yanasse HH. Special issue on cutting, packing and related problems. Int Trans Oper Res 2009;16:659.

[21] Nonas SL, Thorstenson A. A Combined cutting-stock and lot-sizing problem. Eur J Oper Res 2000;120:327-42.

[22] Nonas SL, Thorstenson A. Solving a combined cutting-stock and lot-sizing problem with a column generating procedure. Comput Oper Res 2008;35:3371-92.

[23] Poldi KC, de Araujo SA. Mathematical models and a heuristic method for the multiperiod one-dimensional cutting stock problem. Ann Oper Res 2016;238:497-520.

[24] Poldi KC, Arenales MN. O problema de corte de estoque unidimensional multiperíodo. Pesqui Oper 2010;30:153-74.

[25] Poltroniere SC, Poldi KC, Toledo FMB, Arenales MN. A coupling cutting stock lot sizing in the paper industry. Ann Oper Res 2008;157:91-104. 
[26] Rangel S, Figueiredo A. O problema de corte de estoque em indústria de móveis de pequeno e médio portes. Pesq Oper 2008;28:451-72.

27] Respício A, Captivo ME. Integrating the cutting stock problem in capacity planning. Department of Informatics and Centre of Operational Research, University of Lisbon-Portugal; 2002. p. 1-11.

[28] Santos SMPG, Araujo SA, Rangel S. Integrated cutting machine programming and lot sizing in furniture industry. Pesq Oper desenvolvimento 2011:3:1-17.

[29] SEBRAE. Serviço Brasileiro de Apoio á Micro e Pequena Empresa. (〈http://www sebrae.com.br/uf/goias/indicadoresdas-mpe/classificacao-empresarial $\rangle$. Access: 24 June 2015); 2013.

[30] Silva CTL, Alem Junior DJ, Arenales MN. A combined cutting stock and lot-sizing problem in the small furniture industry. In: International Conference on Operational Research for Development-ICORD VI; 2007.

[31] Silva E, Alvelos F, Valério de Carvalho JM. An integer programming model for twoand three-stage two-dimensional cutting stock problems. Eur J Oper Res Soc 2010;205:699-708.

[32] Silva E, Alvelos F, Valério de Carvalho JM. Integrating two-dimensional cutting stock and lot-sizing problems. J Oper Res Soc 2014;65:108-23.

[33] SPDR. Secretaria de Planejamento e Desenvolvimento Regional, 2012 Caracterização Socio Economica de São Paulo Região Administrativa de São José do Rio Preto, outubro. 76p. 〈http://www.planejamento.sp.gov.br/noti_anexo/files/ uam/trabalhos/SJ\%20Rio\%20Preto.pdf); 2012 [Access: 14 June 2015].
[34] Toscano A, Rangel S, Yanasse HH. A heuristic approach to minimize the number of saw cycles in small-scale furniture factories. Ann Oper Res. [online first: 2015]. http://dx.doi.org/10.1007/s10479-015-1955-9.

[35] Vanzela AM. Problema Integrado de Dimensionamento de Lotes e Corte de Estoque na Indústria Moveleira. (Master dissertation), Unesp, São José do Rio Preto-SP, Brazil. 〈http://www.dcce.ibilce.unesp.br/pos/webfacil/publico/File/mdl_alunos diss 633 0.pdf); 2012 [Access: 14 June 2015].

[36] Vanzela M, Rangel S, Araujo SA. The integrated lot sizing and cutting stock problem in a furniture factory. In: 11th IFAC workshop on intelligent manufacturing systems, São Paulo. Intelligent Manufacturing Systems, vol. 11; 2013. p. 390-5 [received the award "Best Industrial Paper"]

[37] Wagner BJ. A genetic algorithm solution for one-dimensional bundled stock cutting. Eur J Oper Res 1999;117:368-81.

[38] Wäscher G, HauBner H, Schumann H. An improved typology of cutting and packing problems. Eur J Oper Res 2007;183:1109-30.

[39] Yanasse HH, Harris RG, Zinober ASI. Uma heurística para a redução do número de ciclos de serras no corte de chapas. In XIII ENEGEP - Congresso Latino Americano de Engenharia Industrial, São Carlos-SP, Brazil; 1993.

[40] Yanasse HH, Morabito R. Linear models for 1-group two-dimensional guillotine cutting problems. Int J Prod Res 2006;44:3471-91.

[41] Yanasse HH, Morabito R. A note on linear models for two-group and three-group two-dimensional guillotine cutting problems. Int J Prod Res 2008;46:6189-206. 